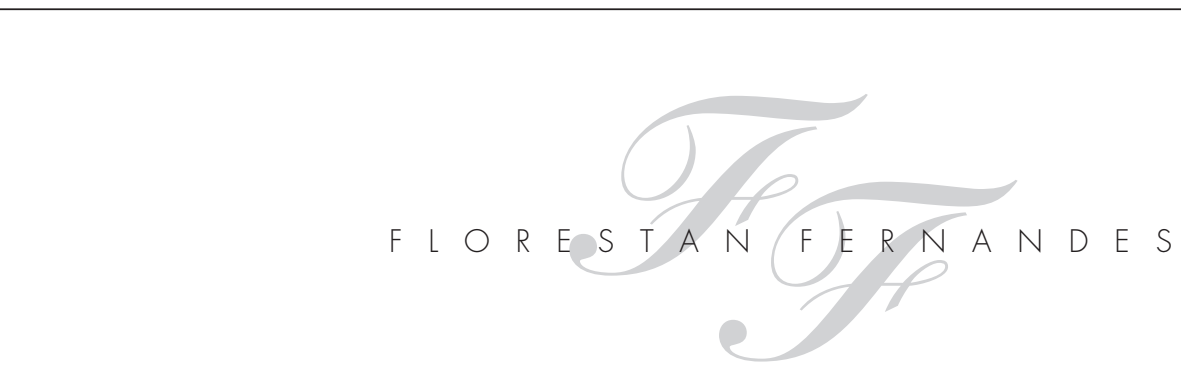

\title{
O ARDIL DOS POLÍTICOS
}

\author{
FLORESTAN FERNANDES
}

$N$

ada soa mais falso que um político profissional querer passar-se como não sendo "político". Um curriculum completo faz fé. Alguém que se dobrou à ditadura, prestou-lhe serviços (e foi por ela recompensado), anuiu ao papel de escudeiro de Paulo Salim Maluf e engalanou-se com o seu reconhecimento de valor, fruto do PDS em sua fase de "maior partido do Ocidente" e agente da sua atividade, com uma carreira que abrange postos no Legislativo e no Executivo, jamais poderia retratar-se como o avesso do político. Não há memória histórica no Brasil e essa circunstância favorece a circulação de mentiras nada convencionais. Porém, toda opçãoim- plica um preço político e ideológico. Realizála e negar-se ao crivo da verdade define o pior tipo de oportunismo político, que infelizmente grassa em nossa terra como tiririca. Porque repousa em um profissionalismo político tradicionalista, o qual confere ao político a liberdade de prometer tudo, de recorrer ao clientelismo, ao paternalismo, ao mandonismo e, conforme as condições conjunturais, ao populismo e à demagogia - e depois dar o dito por não dito, curvando-se ao reacionarismo, ao conservadorismo, ao culto narcisístico do ego e do poder. Sujeito diligente da reprodução da ordem, da associação entre arcaico e moderno, assim se caracteriza o perfil do político tradicionalista na Revista USP nº 3, em 1989, pp. 143-4. brasileiro, servo de sua 


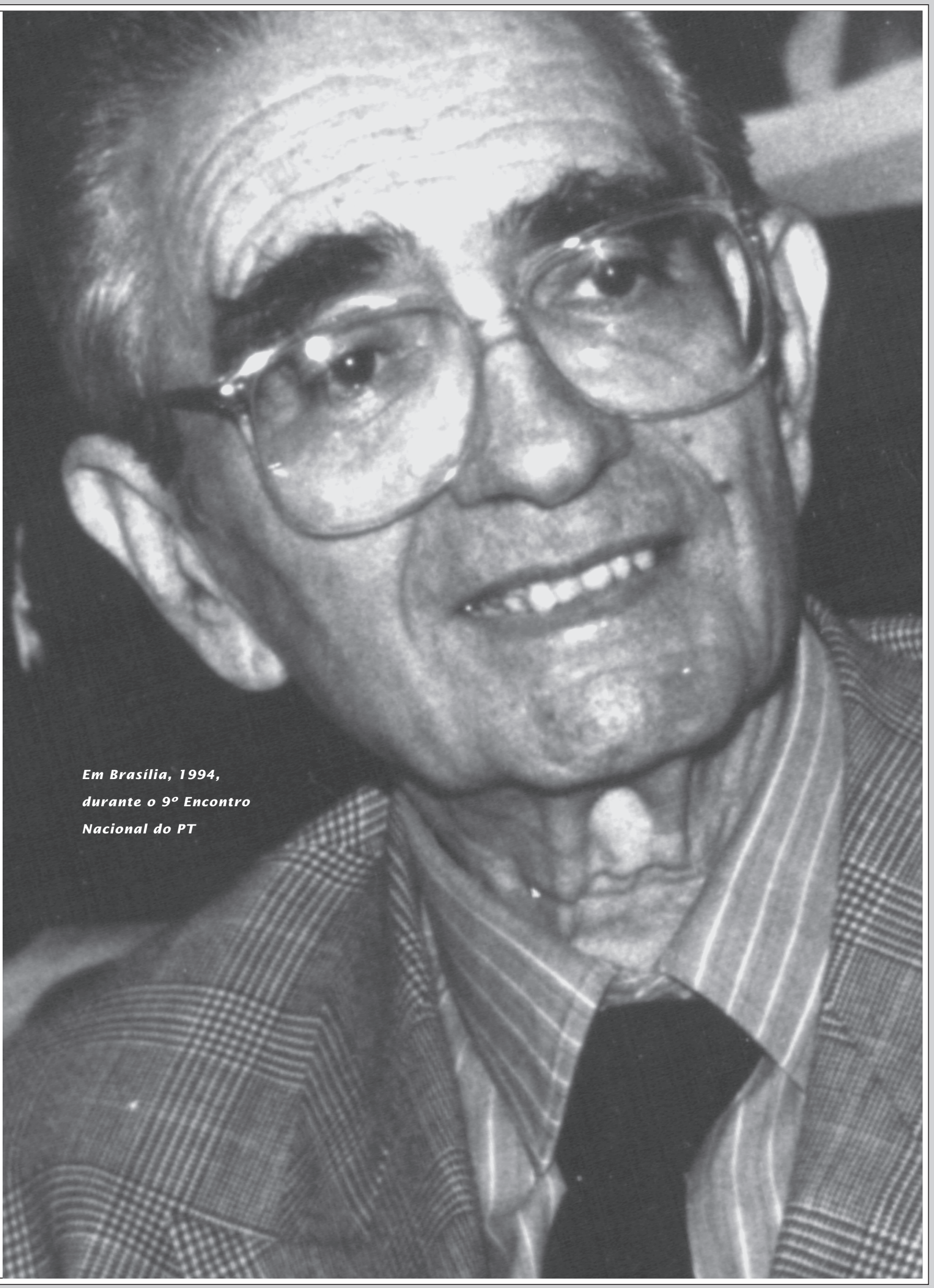


grei e de seus próprios interesses ou alvos pessoais.

Penso que é impossível interpretar a posição do sr. Fernando Collor de Mello de outra maneira, de uma perspectiva psicossociológica. $\mathrm{O}$ politicismo cansou o povo, repugna os cidadãos revoltados contra a manipulação do poder estatal. O candidato assumiu o antipoliticismo e lançou-se à arena eleitoral como ferrenho adversário do politicismo, ignorando sua longa e comprovada vocação politicista. Combater Sarney nãoé, nos dias que correm, a única virtude - nem mesmo a principal virtude - de um candidato à Presidência que deva merecer uma escolha refletida. Nenhum político autêntico pode deixar sem resposta o que significa o Estado de transiçãoprolongada (e isso importa em condenar um governo desacreditado e seu chefe nominal). No entanto, o sr. José Sarney Costa e o sr. Fernando Collor de Mello não são apenas "farinha do mesmo saco". Ambos estão congenitamente presos aum provincianismo constrangedore aparecem, apesar das animosidades recíprocas, como irmãos siameses na arte da política tradicionalista. Não que um revele, hoje, o que o outro será amanhã. O dilema é mais grave. Ambos são portadores de uma mentalidade política análoga e refletem um molde comum, do qual jamais poderia nascer um estadista e que tem infestado o Brasil como uma praga devastadora. Desse ângulo, um se contrapõe ao outro no estilo dos desentendimentos provincianos e da ordem das bicadas: o espaço histórico não comporta os dois, enquanto seus objetivos forem divergentes. Depois... Ora, depois, pior para nós!

É trágico que semelhante figura seja fisgada para a produção em massa da imagem do candidato ideal à Presidência. Ficamos de novo atados aos arcaísmos do passado remoto e recente. Se a farsa continuar e conseguir êxito, perderemos mais uns dez ou vinte anos de nossa história, sem falar que a transição lenta, gradual e segura permanecerá garantida em suas bases políticoadministrativas indefinidamente. Não haverá a sonhada ruptura com o estado de coisas existente e tampouco a necessária revolução democrática se instaurará com a rapidez indispensável. Continuaremos no mais ou menos, nas ilusões de mudanças iminentes, que sempre serão proteladas, para "garantir a paz social". Em suma, através desses espécimes de pró-homens improvisados as elites das classes dominantes fazem fria e calculadamente o seu jogo, como se fossem capazes de criar história. Quando o povo descobrir o engodo, será tarde e as mesmas artimanhas serão reativadas sob outros artifícios mais atraentes, agora graças à modernização e à “cultura da comunicação em massa". Será tudo tão simples? O povo nunca passará de bigorna a malho? E quando isso transcorrer, que cabeças rolarão, que interesses de classes terão de ser soterrados, que mundo social acabará destruído? O uso e o abuso de técnicas sociais ultrapassadas envolvem riscos insondáveis, em um certo momento, e as forças sociais que constroem a história de uma nação com desenvolvimento capitalista desigual não estão à venda nem podem ser controladas a partir de um centro inviolável de poder. Se fosse assim, não haveria Revolução Russa, Revolução Chinesa ou Revolução Cubana. "Se arrependimento matasse", as elites cegas e paralíticas diante dos enigmas históricos enfrentados por seus estamentos ou por suas classes e por suas nações ainda exerceriam o monopólio do poder, da riqueza e da cultura...

Voltemos ao tema deste artigo. É cedo para dizer quem sairá vencedor nas próximas eleições presidenciais. Porém, não possuímos a cultura cívica e a estabilidade política dos Estados Unidos e do Canadá para "pré-fabricar" presidentes ou primeiros-ministros, como se fossem sabonetes, perfumes ou roupas da moda. "Fabricar um presidente", nas condições concretas do Brasil atual, constitui uma ação irresponsável e temerária. Dadas as minhas convicções políticas, deveria escreverexatamente o inverso. Mas, por que provocar riscos prematuros e explosivos, que não servirão para nada, a não ser para conter os ritmos de nosso desenvolvimento econômico, tecnológicoe cultural? Para que fomentar saídas ilusórias, que aumentarão o desespero dos de baixo e sua exasperação, decuplicando o desamor ao País e o ódio à política, em troca de nada? Não é ainda certo que a forjicação de um candidato pré-fabricado prepondere. Todavia, para se instaurar uma democracia com dois pólos contraditórios ativos, um burguês e outro operário, temos de apagar páginas amargas e demolir hábitos e técnicas de dominação política ou de hegemonia cultural que são por si mesmos destrutivos (e, ainda mais, aniquiladores por seus efeitos e continuidade). Nada tenho pessoalmente contra o sr. Fernando Collor de Mello. Entretanto, desde criança aprendi pela experiência o que significa sua prática e sua fraseologia vazia "antipoliticistas". Temos de enveredar por caminhos novos - desafiar o presente e o futuro. As ambiguiidades e as astúcias dos políticos que pretendem pairar "acima das classes" bloqueiam tais caminhos e nos condenam aocaldeirão fervente de uma ordem social fechada dentro do mundo sem humanidade de sua imensidão de iniqüidades. 